\title{
Role of Gliclazide MR in the Management of Type 2 Diabetes: Report of a Symposium on Real-World Evidence and New Perspectives
}

\author{
Kamlesh Khunti · Mohamed Hassanein · Moon-Kyu Lee • \\ Viswanathan Mohan · Aslam Amod
}

Received: April 6, 2020 / Published online: May 21, 2020

(C) The Author(s) 2020

\begin{abstract}
In patients with type 2 diabetes mellitus (T2DM) who require additional glucose-lowering on top of first-line metformin monotherapy, sulfonylureas are the most common choice for second-line therapy followed by dipeptidyl peptidase inhibitors (DPP-4i). This article summarises presentations at a symposium entitled "Real-World Evidence and New Perspectives with Gliclazide MR" held at the International
\end{abstract}

Digital Features To view digital features for this article go to https://doi.org/10.6084/m9.figshare.12205808.

K. Khunti

Diabetes Research Centre, University of Leicester, Leicester, UK

M. Hassanein

Department of Endocrinology, Dubai Hospital, Dubai, United Arab Emirates

\section{M.-K. Lee}

Division of Endocrinology and Metabolism, Department of Internal Medicine, Soonchunhyang University Gumi Hospital-Soonchunhyang

University School of Medicine, Gumi,

Kyungsangbuk-do 39371, South Korea

V. Mohan $(\bowtie)$

Madras Diabetes Research Foundation, Chennai, India

e-mail: drmohans@diabetes.ind.in

A. Amod

Life Chatsmed Garden Hospital and Nelson R.

Mandela School of Medicine, Durban, South Africa
Diabetes Federation Congress in Busan, South Korea on 4 December 2019. Although guideline recommendations vary between countries, the guidelines with the highest quality ratings include sulfonylureas as one of the preferred choices as second-line therapy for T2DM. Data from randomised controlled trials (RCTs) have consistently demonstrated that sulfonylureas are effective glucose-lowering agents and that the risk of severe hypoglycaemia with these agents is low. In addition, both RCTs and realworld observational studies have shown no increased risk of mortality or cardiovascular disease with the use of newer-generation sulfonylureas compared with other classes of glucose-lowering treatments. However, differences between sulfonylureas do exist, with gliclazide being associated with a significantly lower risk of mortality or cardiovascular mortality compared with glibenclamide, as well as the lowest incidence of severe hypoglycaemia compared with other agents in this class. Recent realworld studies into the effectiveness and safety of gliclazide appear to confirm these findings, and publication of new data from these studies in patients with T2DM in the UK, and in Muslim patients who are fasting during Ramadan, are awaited with interest. Another study being undertaken with gliclazide is a pan-India study in patients with maturity-onset diabetes of the young (MODY) subtypes 1, 3 and 12 . Patients with these MODY subtypes respond particularly well to sulfonylurea treatment, and 
sulfonylureas are the first-line agents of choice in these patients. These new and ongoing studies will add to the cumulative data on the efficacy and safety of certain sulfonylureas in patients with diabetes.

Keywords: Gliclazide MR; Guidelines; Maturity onset diabetes of the young; Ramadan; Sulfonylureas; Type 2 diabetes

\section{Key Summary Points}

Why carry out this study?

Sulfonylureas are consistently the most common choice for second-line therapy in patients with type 2 diabetes mellitus (T2DM) who require additional glucoselowering during metformin monotherapy.

In this article we describe presentations given at a symposium held at the International Diabetes Federation Congress in Busan, South Korea (December 2019) that examined the place of sulfonylureas generally, and gliclazide modified release (MR) specifically, in the current treatment paradigm for people with T2DM.

\section{What was learned from the study?}

Newer generation sulfonylureas, such as gliclazide MR, are effective, well-tolerated and accessible treatments for T2DM, and recommended in the early management of people with T2DM.

Among the available sulfonylureas, gliclazide is associated with the greatest beneficial impact on cardiovascular mortality, and the lowest incidence of severe hypoglycaemia.

\section{INTRODUCTION}

Sulfonylureas have been used clinically to treat type 2 diabetes mellitus (T2DM) since the 1960s [1], and are still among the most commonly prescribed oral diabetic treatments [2]. Data on prescription patterns globally show that sulfonylureas are consistently the most common choice for second-line therapy in patients who require additional glucose-lowering during metformin monotherapy, followed by dipeptidyl peptidase 4 inhibitors (DPP-4i) [2, 3].

Treatment guidelines for T2DM are regularly updated to include emerging treatments and evolving evidence, especially from cardiovascular outcomes trials (CVOTs). Yet, there are significant differences between guidelines in the recommendations related to sulfonylureas [4-11].

In this article, we describe presentations at a symposium held at the International Diabetes Federation Congress in Busan, South Korea on 4 December 2019. These presentations examined the place of sulfonylureas generally, and gliclazide modified release (MR) specifically, in the current treatment paradigm for people with T2DM. Guideline recommendations for the use of sulfonylureas are described and the evidence supporting these recommendations is critically evaluated, and recent real-world evidence is reviewed on the efficacy and safety of gliclazide $\mathrm{MR}$, including in special populations of patients, such as T2DM patients who undertake daytime fasting during Ramadan and patients with maturity onset diabetes in the young (MODY).

This article is based on previously conducted studies and does not contain any studies with human participants or animals performed by the authors.

\section{PLACE OF SULFONYLUREAS IN CURRENT TREATMENT GUIDELINES}

Diabetes guidelines worldwide almost universally recommend metformin as the first-line glucose-lowering drug in newly diagnosed 
patients with T2DM, but they vary in terms of the recommendations about which agents should be used as add-on therapies if metformin alone cannot achieve glycaemic targets (Table 1) [4-6, 8, 10-12]. In patients with established atherosclerotic cardiovascular

Table 1 Summary of consensus report recommendations on the use of sulfonylureas and gliclazide MR in patients without established atherosclerotic cardiovascular disease

\begin{tabular}{|c|c|c|}
\hline Diabetes guidelines & $\begin{array}{l}\text { Second-line treatment recommendation in } \\
\text { patients with suboptimal glucose control on } \\
\text { metformin }\end{array}$ & $\begin{array}{l}\text { Guideline information specific to } \\
\text { gliclazide MR }\end{array}$ \\
\hline $\begin{array}{l}\text { UK (NICE/SIGN) } 2015^{\mathrm{a}} \\
\text { [11] }\end{array}$ & $\begin{array}{l}\text { Add DPP-4i, pioglitazone or SU } \\
\text { GLP-1RAs not recommended }\end{array}$ & - \\
\hline $\begin{array}{l}\text { South Asian Federation } \\
\text { of Endocrine Societies } \\
2015[10]\end{array}$ & Add SU as second-line agents of choice & $\begin{array}{l}\text { Gliclazide MR or glimepiride are } \\
\text { preferred over conventional SU }\end{array}$ \\
\hline $\begin{array}{l}\text { Australia (RACGP and } \\
\text { Diabetes Australia) } \\
\text { 2016-2018 [5] }\end{array}$ & $\begin{array}{l}\text { Add } S U \text { as second-line agents of choice } \\
\text { Another agent may be used if } S U \text { are contraindicated } \\
\text { or not tolerated }\end{array}$ & $\begin{array}{l}\text { Gliclazide less likely to cause } \\
\text { hypoglycaemia compared with } \\
\text { glibenclamide or glimepiride }\end{array}$ \\
\hline $\begin{array}{l}\text { Global (International } \\
\text { Diabetes Federation) } \\
2017 \text { [4] }\end{array}$ & $\begin{array}{l}\text { Preferred add-on therapies are SU (not } \\
\text { glibenclamide/glyburide), DPP-4i or SLGT-2i }\end{array}$ & - \\
\hline $\begin{array}{l}\text { Global resource-limited } \\
\text { settings (WHO) } 2018 \\
{[23]}\end{array}$ & Add an $S U$ & $\begin{array}{l}\text { Gliclazide is preferred SU if } \\
\text { hypoglycaemia is a concern }\end{array}$ \\
\hline $\begin{array}{l}\text { Canada (Diabetes } \\
\text { Canada) } 2018[6]\end{array}$ & Add DDP-4i, GLP-1RA, or SGLT-2i & $\begin{array}{l}\text { If } S U \text { is added to metformin, gliclazide } \\
\text { is the first choice }\end{array}$ \\
\hline $\begin{array}{l}\text { USA/Europe (ADA/ } \\
\text { EASD) } 2018[8]\end{array}$ & $\begin{array}{l}\text { Add SU as second-line agents if cost is a compelling } \\
\text { issue } \\
\text { Reserve SU for fourth-line treatments (after DPP- } 4 \mathrm{i} \text {, } \\
\text { GLP-1RA, SGLT- } 2 \mathrm{i} \text { and/or TZD }{ }^{\mathrm{b}} \text { ) if there is a } \\
\text { compelling need to minimise hypoglycaemia or } \\
\text { weight gain }\end{array}$ & $\begin{array}{l}\text { Gliclazide not licensed in the US for } \\
\text { T2DM }\end{array}$ \\
\hline $\begin{array}{l}\text { Europe (ESC/EASD) } \\
2019[12]\end{array}$ & $\begin{array}{l}\text { Add DDP-4i, GLP-1RA, SGLT-2i or TZD } \\
\text { Reserve SU for fourth-line treatments (after DPP-4i, } \\
\text { GLP-1RA, SGLT-2i and/or TZD) }\end{array}$ & $\begin{array}{l}\text { If using } \mathrm{SU} \text {, choose a later generation } \\
\text { agent to minimise risk of } \\
\text { hypoglycaemia }\end{array}$ \\
\hline
\end{tabular}

$A D A$ American Diabetes Association, DPP-4i dipeptidyl peptidase 4 inhibitors, EASD European Association for the Study of Diabetes, ESC European Society of Cardiology, GLP-1RA glucagon-like peptide 1 receptor agonists, $M R$ modified release, NICE National Institute for Health and Care Excellence, RACGP Royal Australian College of General Practitioners, $S G L T-2 i$ sodium-glucose transport protein 2 inhibitors, $S U$ sulfonylurea, $T 2 D M$ type 2 diabetes mellitus, $T Z D$ thiazolidinedione, $W H O$ World Health Organization

a Updated in 2019

b TZDs not recommended when there is a compelling need to minimise weight gain 
disease, recent guidelines consistently recommend second-line treatment with a sodiumglucose cotransporter 2 inhibitor (SGLT-2i) or a glucagon-like peptide-1 receptor agonist (GLP1RA) $[6,8,12]$, based on data from the largescale CVOTs showing that these agents reduced the risk of major adverse cardiovascular events (MACE) in patients with diabetes and cardiovascular disease (CVD) [13-22].

For patients without established CVD, the recommendations for add-on glucose-lowering therapy differ between guidelines. Australian, Indian and World Health Organization guidelines specify sulfonylureas as the agents of choice for second-line therapy $[5,10,23]$, while guidelines from the National Institute for Health and Care Excellence (NICE) in the UK and the International Diabetes Federation (IDF) include sulfonylureas as one of the preferred options, along with a DPP-4i and either pioglitazone (UK) or a SGLT-2i (IDF) [4, 11]. In contrast, the consensus report from the American Diabetes Association (ADA) and European Association for the Study of Diabetes (EASD) recommends sulfonylureas as second-line therapy only if cost is a compelling issue [8]. These consensus recommendations, as well as joint guidelines from the EASD and the European Society of Cardiology (ESC), place sulfonylureas as a fifth-line treatment after other classes of oral glucose-lowering drugs have been tried $[8,12]$.

\section{Why the Differences Between Guidelines?}

Some may speculate that the guidelines recommending sulfonylureas as the preferred second-line agents do so because of cost. Certainly, sulfonylureas have a low drug acquisition cost compared with other classes of glucose-lowering agents [24], but to consider that the recommendations are driven by cost alone ignores the well-established efficacy and safety profile of sulfonylureas. As a class, these agents differ in their pharmacokinetic characteristics (Table 2) $[10,25]$. The recommendation for sulfonylureas in the Canadian guidelines is based on a thorough assessment of clinical benefits, quality of life, safety concerns, cost and resource use undertaken by the Canadian Agency for Drugs and Technologies in Health (CADTH) [26]. This analysis found that the sulfonylurea gliclazide ranked number one in all comparisons because it worked as well as other classes of glucoselowering drugs but cost the least [26]. Another reason for the difference between consensus recommendations may be related to the way in which they are developed. Not all reports are developed using strict rigour in their collection and/or assessment of the evidence. In the ADA/ EASD guidelines, for example, the authors themselves write: “...though evidence based, the recommendations presented herein are the opinions of the authors" [8]. Various bodies have developed standards for clinical practice guidelines, including the Institute of Medicine in the USA [27] and the Appraisal of Guidelines for Research and Evaluation (AGREE) consortium in Canada [28]. These standards focus on the process, sources, flexibility, validity, reliability and applicability of the recommendations [27], and have led to the development of the AGREE II instrument that can be used to rate the quality of clinical guidelines [28]. Using this instrument, the IDF ranked the recommendations from a variety of different bodies [4]: the highest ranked guidelines for diabetes were the NICE guidelines from the UK (97\%), which recommend sulfonylureas as the first choice for add-on therapy. In contrast, the ADA guidelines and the American Association for Clinical Endocrinology (AACE) guidelines scored a total of 50 and $36 \%$, respectively, with particularly low scores for scientific rigour $(28 \%$ for ADA and $6 \%$ for AACE guidelines) [4]. This suggests that the reputation and popularity of the organisation developing the guidelines may not necessarily reflect the level of the evidence used to make the recommendations.

\section{Sulfonylureas and Cardiovascular Disease}

The EASD/ADA and ESC/EASD consensus guidelines recommend second-line treatment with newer agents (SGLT-2i and GLP-1RA) based on the evidence from CVOTs $[8,12]$. These guidelines reserve sulfonylureas for fifthline therapy after newer agents have been tried, 


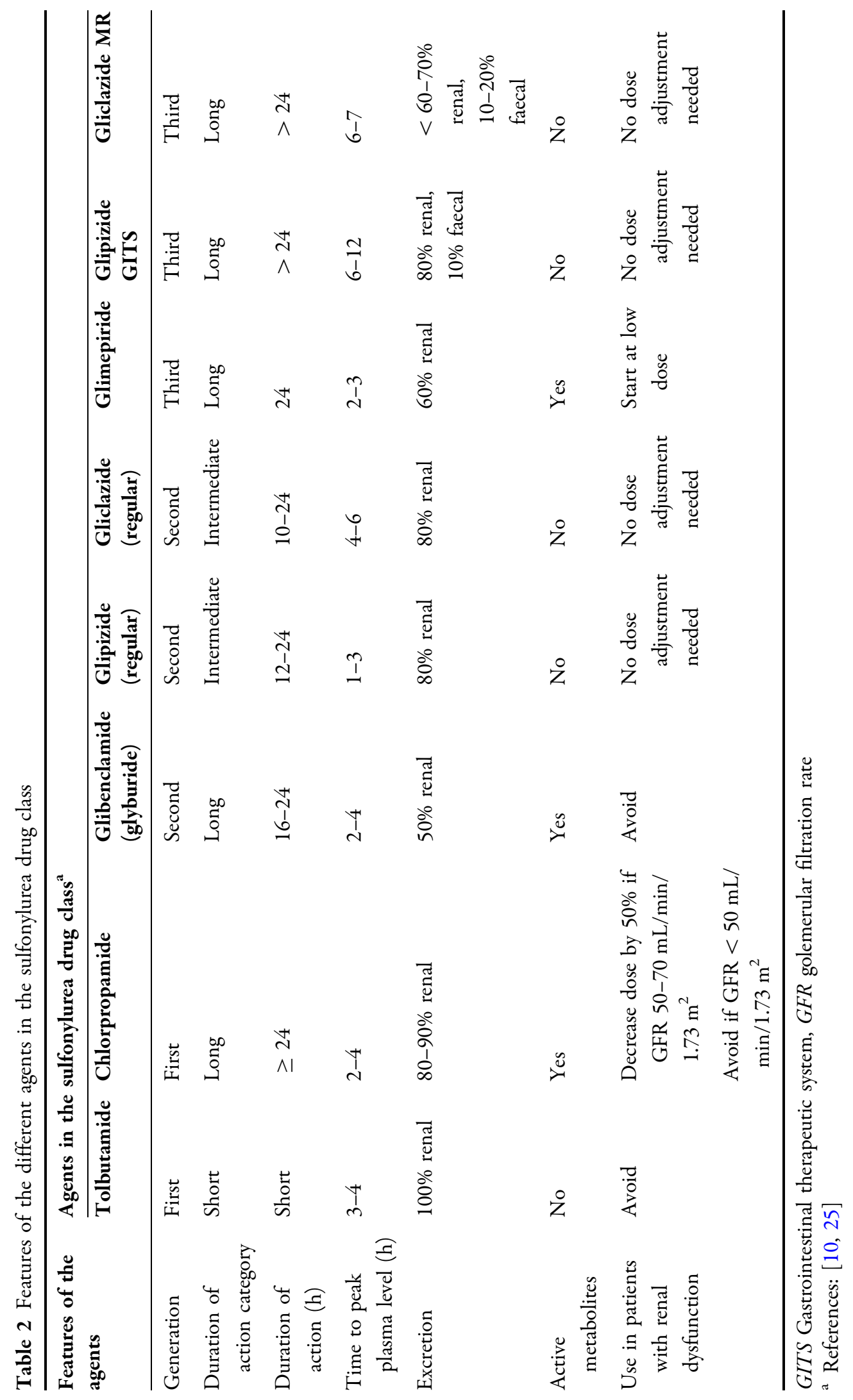


and cite results from observational studies which suggest an increased risk of CVD with sulfonylureas compared with other classes of glucose-lowering drugs [29, 30].

However, the compelling benefit of SGLT-2i and GLP-1RAs has only been demonstrated in patients with established CVD-and not in patients with multiple risk factors for CVD [31]. Moreover, most T2DM patients seen in clinical practice (60-92\%) would not meet the eligibility criteria for inclusion SGLT-2i or GLP-1RA CVOTs due to their disease characteristics/comorbid conditions [32-37], calling into question the generalisability of these studies to a wider clinical practice population.

The risk of CVD seen with sulfonylureas in some observational studies [38, 39] has not been demonstrated in randomised controlled trials (RCTs), including the TOSCA-IT, CAROLINA, ADVANCE and ADOPT studies [40-43]. TOSCA.IT and CAROLINA showed that a sulfonylurea was noninferior to pioglitazone and linagliptin, respectively, for preventing MACE $[41,42]$. In the CAROLINA study, not only was the incidence of the composite endpoint of MACE similar in the sulfonylurea (glimepiride) and DPP-4i arms, but so was the incidence of each individual component of the composite endpoint (cardiovascular death, nonfatal myocardial infarction [MI], and nonfatal stroke) [41]. Importantly, data from a retrospective analysis of real-world outcomes suggest that sulfonylureas and DPP-4i do indeed have a similar impact on cardiovascular outcomes, as seen in the CAROLINA study [44].

It is also worth noting that sulfonylureas were the major second-line class of glucoselowering agents used in the large-scale trials that demonstrated the importance of intensive glucose-lowering for delaying the development of macrovascular events in patients with T2DM, such as the UK Prospective Diabetes Study (UKPDS) and ADVANCE $[45,46]$. In ADVANCE, intensive glucose-lowering with a combination metformin + sulfonylurea-based regimen also reduced the risk of microvascular events, and the impact of intensive treatment of microvascular and macrovascular outcomes was similar in patients with different levels of baseline renal function [43].
Overall, the weight of the evidence indicates no increased risk of mortality or CVD with the use of sulfonylureas compared with other classes of glucose-lowering treatments [47]. Moreover, examination of the relationship between individual sulfonylureas and CVD outcomes revealed that the lowest risk appears to be associated with gliclazide [48]. A meta-analysis of sulfonylurea studies demonstrated that gliclazide was associated with a significantly lower risk of cardiovascular mortality (relative risk [RR] $0.60 ; 95 \%$ confidence intervals [CI] 0.45-00.84) and all-cause mortality (RR 0.65; 95\% CI 0.53-0.79) compared with glibenclamide and others (Fig. 1) [48].

\section{Sulfonylureas and Severe Hypoglycaemia}

Another concern sometimes expressed about the sulfonylureas is the risk of hypoglycaemia. Severe hypoglycaemia is associated with an increased risk of mortality $[46,49,50]$, but no causal relationship between hypoglycaemia and mortality has been proven. A more likely explanation is that severe hypoglycaemia is a marker for comorbidity or illness severity. This is borne out by data from RCTs showing a difference in the incidence of severe hypoglycaemia between treatment arms, but no difference in the risk of CVD or mortality [41, 42, 51, 52].

For example, in the CAROLINA study, the risk of MACE was similar in the glimepiride and the linagliptin arms (hazard ratio [HR] 0.95; 95\% CI $0.84-1.14 ; p<0.001$ for non-inferiority), as was the risk of mortality (HR 0.94; 95\% CI $0.78-1.06$; $p=0.23$ ), but the rate of hypoglycaemia was significantly lower in the linagliptin than in the glimepiride arm (HR 0.23; 95\% 0.21-0.26; $p<0.001$ ) [41]. If hypoglycaemia were causally linked with death, it would be expected that this would be reflected in the mortality outcomes of the CAROLINA study. Another notable element of the CAROLINA study was that it involved a high-risk population for hypoglycaemia, including 35\% patients with established CVD, 37\% at high cardiovascular risk, $19 \%$ aged $\geq 70$ years and $18 \%$ with stage 3 chronic kidney disease [53]. 


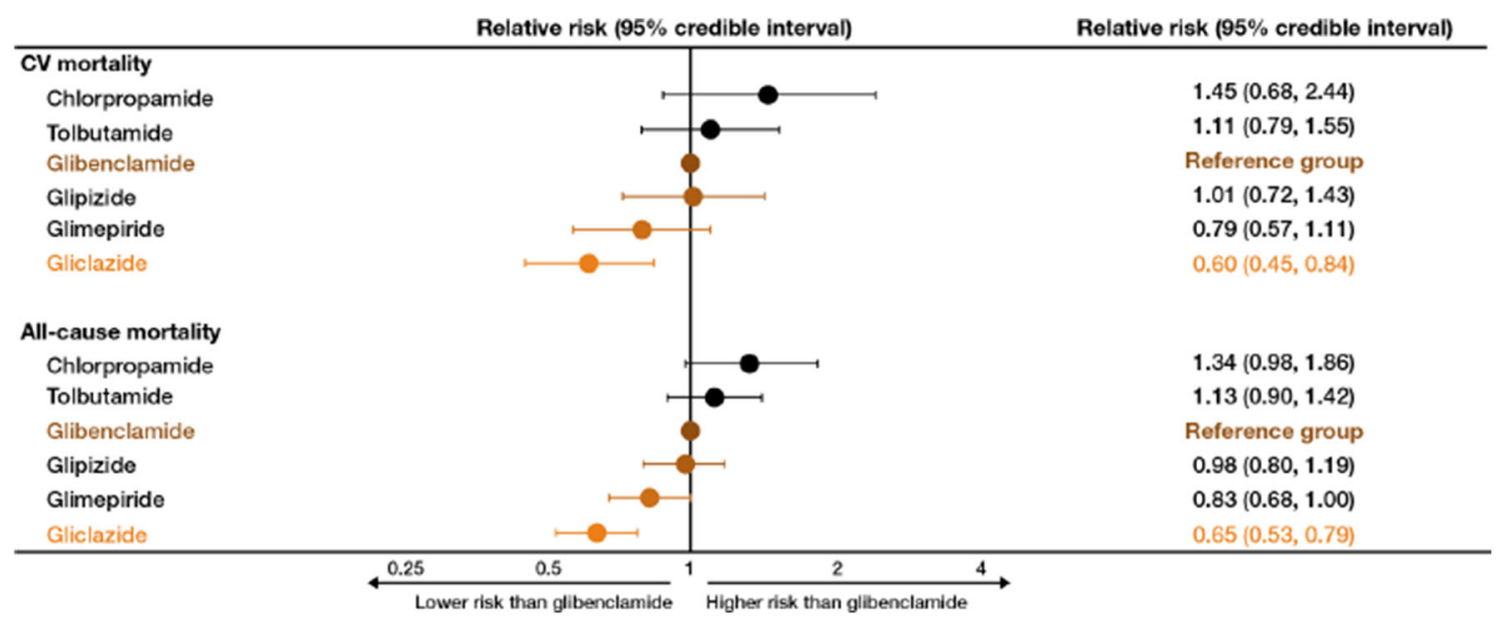

Fig. 1 Comparison of all-cause mortality between different sulfonylureas based on direct and indirect evidence [48]. Data are pooled and analysed by network meta-

In fact, the absolute risk of severe hypoglycaemia with the sulfonylureas in RCTs is low, particularly with the later-generation agents, such as gliclazide (Table 3) [41, 42, 54-56]. Gliclazide is available in a regular, intermediateacting formulation and a long-acting MR formulation (Table 2). The MR formulation uses a hydrophilic polymer base to release gliclazide analysis. Reference agent is glibenclamide. $C V$ Cardiovascular. (Reprinted from Lancet Diabetes Endocrinol., [48] Copyright (2015), with permission from Elsevier)

progressively over $24 \mathrm{~h}$, allowing once-daily dosing [57]. Based on the data from randomised trials, at least 232 patients would need to be treated with a sulfonylurea to cause one severe hypoglycaemic event (number needed to harm [NNH]), and the NNH for gliclazide MR specifically is 333 [41, 42, 54-56]. The low risk of symptomatic hypoglycaemia is supported by

Table 3 Absolute risk of severe hypoglycaemia in randomised controlled trials with sulfonylureas

\begin{tabular}{|c|c|c|c|c|}
\hline Randomised controlled trials & Duration (years) & Treatments & $N$ & $\begin{array}{l}\text { Rate of severe } \\
\text { hypoglycaemia }\end{array}$ \\
\hline \multirow[t]{2}{*}{ GUIDE 2004 [56] } & 0.52 & Gliclazide MR & 405 & 0 \\
\hline & & Glimepiride & 440 & 0 \\
\hline \multirow[t]{2}{*}{ ADVANCE 2008 [55] } & 5.0 & $\begin{array}{l}\text { Gliclazide MR-based } \\
\text { intensive control }\end{array}$ & 5571 & 2.7 \\
\hline & & Standard control & 5569 & 1.5 \\
\hline \multirow[t]{2}{*}{ Foley et al. 2009 [54] } & 2.0 & Gliclazide & 546 & 0 \\
\hline & & Vildagliptin & 546 & 0 \\
\hline \multirow[t]{2}{*}{ TOSCA.IT 2017 [42] } & 4.8 & Sulfonylurea ${ }^{a}$ & 1493 & 1.61 \\
\hline & & Pioglitazone & 1535 & 0.06 \\
\hline \multirow[t]{2}{*}{ CAROLINA 2019 [41] } & 6.3 & Glimepiride & 3010 & 2.2 \\
\hline & & Linagliptin & 3023 & 0.1 \\
\hline
\end{tabular}

a Gliclazide $(n=745)$, glimepiride $(n=723)$ or glibenclamide $(n=24)$ in accordance with local practice 
data from a prospective observational study of primary care T2DM patients in the UK [58]. This study showed a risk of hypoglycaemia (blood glucose $<3.0 \mathrm{mmol} / \mathrm{L}$ ) of 0.12 per person-year with sulfonylureas, similar to the rate with incretin-based therapy (0.04 per person-year) and much lower than the rate with insulin (1.03 per person-year) [58].

Moreover, the risk of hypoglycaemia varies between sulfonylureas. A recent meta-analysis demonstrated that the relative risk of hypoglycaemia with gliclazide versus placebo (3.9) is more similar to the risk with metformin (2.0) than it is to the risk with other sulfonylureas such as glimepiride (8.9), glyburide (10.2) or glipizide (13.9) [59]. The risk of hypoglycaemia can be mitigated by avoiding sulfonylureas in high-risk patients, such as elderly or frail patients, those with advanced organ dysfunction or those with a previous history of severe hypoglycaemia.

\section{Sulfonylureas and Weight Gain}

Another reason why some guidelines may recommend newer agents ahead of sulfonylureas is that SGLT-2i and GLP-1RA are associated with weight loss, while sulfonylureas and thiazolidinediones are associated with modest weight gains [59]. In clinical trials, the average weight loss was $1.5-2.4 \mathrm{~kg}$ with maximal doses of SLGT2i [59-63] and between 0.9 and $1.8 \mathrm{~kg}$ with maximal doses of GLP-1RA [59]. For many patients, weight loss is a desirable side effect of treatment, but there are no data to indicate that the modest loss achieved with SGLT-2i or GLP1RA contributes to improvements in glycaemic response or clinically measurable outcomes. There was no weight gain with gliclazide MR in the ADVANCE study over a 5-year period.

\section{ROLE OF SULFONYLUREAS IN A REAL-WORLD POPULATION}

As described earlier, the effectiveness and safety of sulfonylureas has been demonstrated in some real-world studies, including data showing that the sulfonylureas and DPP-4i have similar effects on outcomes [44]. However, data from observational studies performed in the USA using glimepiride may not be applicable in the UK where gliclazide is the most commonly prescribed sulfonylurea.

\section{USE OF SULFONYLUREAS DURING RAMADAN}

Approximately 1.8 billion people in the world are Muslim. For many of these individuals, fasting during the holy month of Ramadan is an important tenet of their faith, but the requirements of Ramadan (no food or drink during daylight hours) can pose a health risk for Muslim patients with diabetes [64]. Because the risk of hypoglycaemia is high during fasting, and many Muslim individuals are reluctant to break their fast if they develop hypoglycaemia, optimal care to reduce risks is important. Physicians can minimise the risk by careful treatment choice, risk stratification and patient education, and by encouraging frequent or continuous glucose monitoring during Ramadan [64].

Patients receiving treatment for T2DM show a higher incidence of hypoglycaemia during Ramadan, and this is true for treatment regimens with or without sulfonylureas [65]. Randomised studies have shown that the risk of symptomatic hypoglycaemia during Ramadan is low in patients receiving stable doses of a sulfonylurea for at least 3 months, and is lower with gliclazide than with glimepiride or glibenclamide (Fig. 2) [66, 67]. In the randomised STEADFAST study, combination therapy with gliclazide + metformin was associated with a similar rate of hypoglycaemia during Ramadan as combination therapy with vildagliptin + metformin [68]. However, these studies were conducted with short-acting gliclazide, so the effect of a newer formulation of gliclazide, gliclazide MR, on hypoglycaemia during Ramadan is unknown. The DIA-RAMADAN study was the first international real-world study to investigate the effects of gliclazide MR [69].

The DIA-RAMADAN study was conducted at 64 centres in nine countries (Bangladesh, Egypt, India, Indonesia, Kuwait, Malaysia, Pakistan, 
Al Sifri et al. $2011[66]$

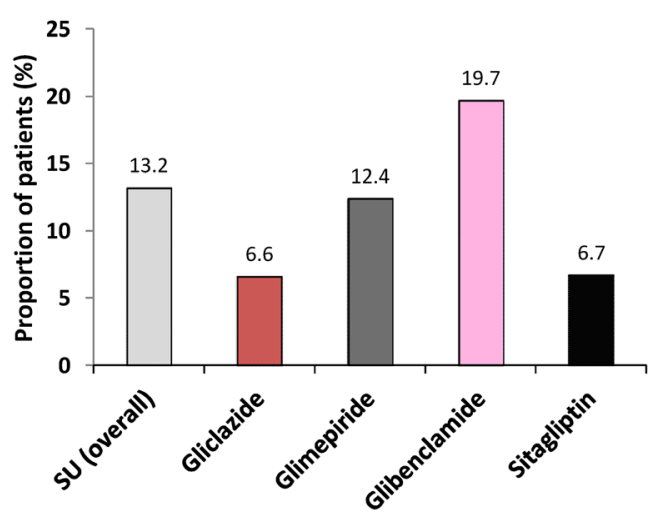

Aravind et al. 2012 [67]

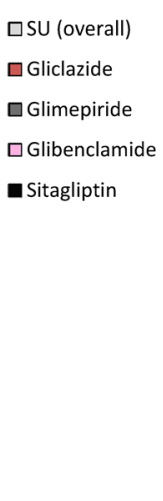

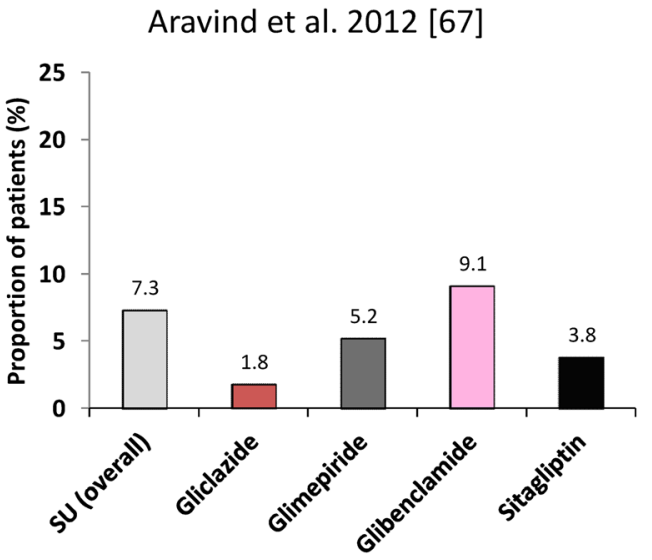

Fig. 2 The incidence of symptomatic hypoglycaemia during Ramadan in patients receiving a SU or sitagliptin in randomised controlled trials. (Data from Al Shifri et al. [66] and Aravind et al [67])

Saudi Arabia and the United Arab Emirates) and enrolled 1214 patients with T2DM who had been receiving gliclazide MR $60 \mathrm{mg}$ /day for at least 90 days before enrolment and who planned to fast during Ramadan. Patients completed diaries during the $6-8$ weeks before Ramadan, the 4.5 weeks of Ramadan and then for 4-6 weeks afterwards. Only patients with glycated haemoglobin $(\mathrm{HbA} 1 \mathrm{c})<9 \%$ were to be included in the study; mean HbA1c was 7.5\% [69]. Approximately $59 \%$ of patients were receiving gliclazide MR in combination with at least one other oral glucose-lowering drug (most commonly metformin or a DPP-4i), but $41 \%$ received gliclazide $\mathrm{MR}$ as monotherapy. The primary endpoint was the development of symptomatic hypoglycaemia (confirmed or unconfirmed), but patients were asked to check their blood glucose during a hypoglycaemic episode to confirm that the symptoms were caused by hypoglycaemia.

The average dose of gliclazide MR during the study was $74 \mathrm{mg}$; approximately two-thirds of patients (66\%) took $60 \mathrm{mg}, 7 \%$ took $90 \mathrm{mg}$ and $22 \%$ took $120 \mathrm{mg}$. Patients fasted for an average of $15 \mathrm{~h}$ a day for 28.7 days. Only 62 patients (5\%) broke their fast for more than 3 consecutive days, but this was mostly for non-medical reasons $(n=45)$ or medical reasons other than hypoglycaemia $(n=15)$; three patients broke their fast due to hypoglycaemia. While hypoglycaemia was more common during Ramadan than in the weeks before or after the fast, the overall rate of symptomatic hypoglycaemia during Ramadan was low (2.2\% compared with $0.2 \%$ before and $0.3 \%$ after Ramadan), as was the rate of confirmed hypoglycaemia (1.6\% vs. $0.2 \%$ before and $<0.1 \%$ after Ramadan). Confirmed hypoglycaemia during Ramadan was much more common among patients who ate $\leq 2$ meals per day compared with patients who ate $>2$ meals per day during Ramadan. No severe hypoglycaemic events occurred [69].

Other outcomes supported the efficacy and safety of gliclazide MR during Ramadan: both HbA1c and bodyweight showed small but significant reductions, no drug-related adverse events occurred and no patient required a dose modification [69]. The DIA-RAMADAN study suggests that gliclazide MR is a safe and effective treatment option for T2DM patients who wish to fast during Ramadan.

\section{USE OF SULFONYLUREAS IN PATIENTS WITH MODY}

Maturity-onset diabetes of the young (MODY) was first described in the 1960s and 1970s as a form of diabetes that developed in young people (generally at an age $<25$ years) but which was distinct from type 1 diabetes because there was clear evidence of genetic inheritance and patients did not require insulin [70, 71]. It was subsequently determined that MODY is a form of monogenic diabetes with autosomal 
dominant inheritance in which the major phenotypic trait is impaired insulin secretion $[70,71]$. More than one subtype of MODY exists, depending on the affected gene, but the most common forms are MODY2 and MODY3, which together account for about $70 \%$ of cases, followed by MODY1, MODY5 and MODY10 (Table 4) [70, 72, 73].

It is important for clinicians to be alert to the possibility of MODY in a young person with diabetes. The principal pathogenic defect in MODY is impaired insulin secretion, so (unlike patients with type 1 diabetes) $99 \%$ of patients with MODY will not have islet cell autoantibodies, and most will show endogenous insulin secretion for some years after diagnosis [73]. As a result, these patients do not require insulin therapy, and those with MODY1 or MODY3 will respond very well to sulfonylureas, which are the agents of choice in these forms of MODY
[73]. A summary of the clinical features of MODY that can assist with differential diagnosis is shown in Table 5. If MODY is suspected, genetic testing should be undertaken to confirm the diagnosis and to help guide treatment decisions [72, 74].

MODY caused by HFN mutations (MODY1, MODY3 and MODY5) responds extremely well to sulfonylureas [73]. These agents should be used as first-line treatment before metformin in patients with MODY because these patients do not have insulin resistance; metformin, as an insulin sensitizer, is better suited for patients with T2DM. This was clearly demonstrated in a crossover trial in which patients with T2DM or MODY3 were randomised to metformin or gliclazide for 6 weeks, and then crossed over to the alternative treatment following a 1-week washout period between treatments [75]. Gliclazide was significantly more effective in lowering

Table 4 Genetics and clinical features of selected subtypes of maturity onset diabetes of the young

\begin{tabular}{|c|c|c|c|}
\hline Subtype $^{\mathrm{a}}$ & $\begin{array}{l}\text { Affected } \\
\text { gene }\end{array}$ & Locus & Clinical features \\
\hline MODY1 & $H F N 4 A$ & $\begin{array}{r}20 \mathrm{q} 12- \\
\mathrm{q} 13.1\end{array}$ & $\begin{array}{l}\text { Represents approx. } 10 \% \text { of MODY cases } \\
\text { Near-normal FPG but abnormal PPG, although FPG worsens over time } \\
\text { Responds well to sulfonylurea agents }\end{array}$ \\
\hline MODY2 & $G C K$ & $7 \mathrm{p} 15-\mathrm{p} 13$ & $\begin{array}{l}\text { Represents approx. } 32 \% \text { of MODY cases } \\
\text { Mild fasting hyperglycaemia often detected incidentally } \\
<50 \% \text { of carriers have overt diabetes mellitus and microvascular complications } \\
\text { are rare }\end{array}$ \\
\hline MODY3 & $H N F 1 A$ & $12 \mathrm{q} 24.2$ & $\begin{array}{l}\text { Most common form (approx. } 52 \% \text { of cases) } \\
\text { Presents clinically like MODY1 }\end{array}$ \\
\hline MODY5 & $H N F 1 B$ & $\begin{array}{r}17 \mathrm{cen}- \\
\mathrm{q} 21.3\end{array}$ & $\begin{array}{l}\text { Represents approx. } 6 \% \text { of MODY cases } \\
\text { Overt diabetes mellitus in association with renal and genitourinary abnormalities }\end{array}$ \\
\hline MODY10 & INS & $11 \mathrm{p} 15.5$ & $\begin{array}{l}\text { Rare }(<1 \% \text { of cases }) \\
\text { Usually associated with neonatal diabetes }\end{array}$ \\
\hline MODY12 & $A B C C 8$ & $11 \mathrm{p} 15.1$ & $\begin{array}{l}\text { Rare }(<1 \% \text { of cases }) \\
\text { Usually associated with neonatal diabetes }\end{array}$ \\
\hline
\end{tabular}

$F P G$ Fasting plasma glucose, $M O D Y$ maturity onset diabetes of the young, $P P G$ postprandial plasma glucose

${ }^{a}$ References: $[70,73,79]$ 
Table 5 Features of maturity onset diabetes of the young that can assist with differential diagnosis

Young age at onset (usually but not exclusively $<25$ years)

Usually non-obese, normotensive and without elevated lipid levels

Clear pattern of inheritance-diabetes present in at least three generations of family, and usually in parents and siblings

Autoantibodies to pancreatic islet cells almost always absent

Insulin reserve evident for some years after diagnosis

Glycosuria at lower than usual blood glucose levels (MODY1, 3 and 5)

Marked sensitivity for sulfonylureas (MODY1, 3 and 5)

Reference: [73]

fasting plasma glucose in the patients with MODY3 than it was in the patients with T2DM, whereas metformin was slightly (but not significantly better) in the T2DM than the MODY3 group (Fig. 3) [75]. In addition, while gliclazide increased $\beta$-cell function by $55 \%$ in patients with T2DM, the increase was $310 \%$ in patients with MODY3 [75].

The profile of T2DM in South Asia, including India, differs from that in Western populations, with a propensity to develop insulin resistance at a younger age and lower body mass index,

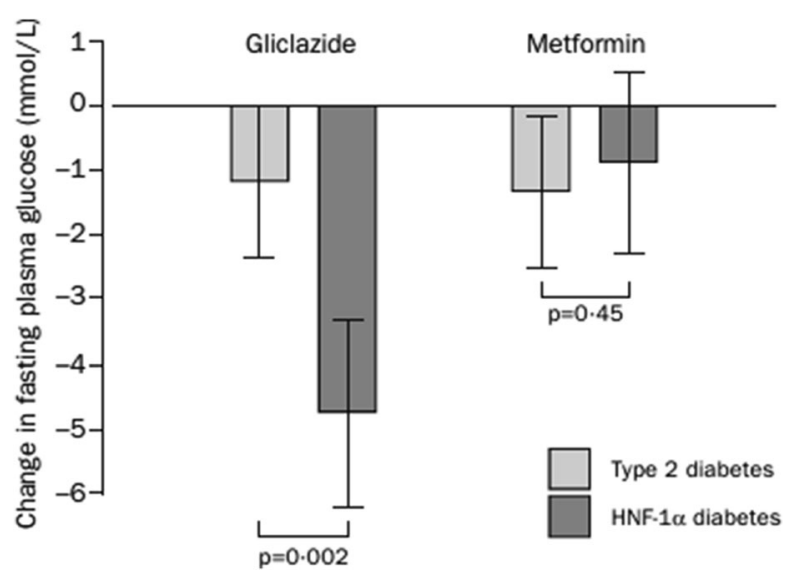

Fig. 3 Change in fasting plasma glucose level after 6 weeks of treatment with gliclazide or metformin in patients with type 2 diabetes or maturity-onset diabetes of the young subtype 3 (MODY3; HNF-1 $\alpha$ diabetes) [75]. Vertical lines indicate $95 \%$ confidence intervals. (Reprinted from Lancet., [75] Copyright (2003), with permission from Elsevier) and a high prevalence of several high-risk genetic polymorphisms [76, 77]. There is also evidence that the epidemiology of MODY differs in India compared with European populations [78]. Genomic data from South India show that, while MODY3 was the most common subtype (as it is elsewhere), the next most common was MODY12, which is associated with a mutation in $A B C C 8$, which is rare in European populations [78]. Since MODY subtype can impact treatment choice, it is important to understand the prevalence of different subtypes in different populations, so a nationwide study of MODY in India is being undertaken.

This Pan-India MODY study is being conducted throughout India between November 2019 and October 2021. There are two parts to the study. Part 1 is a comprehensive genetic screening program for MODY to identify the prevalence of different subtypes, but there is also a substudy within part 1 aimed at investigating whether it is feasible to conduct genetic testing on saliva samples, since it is easier to collect saliva than blood, especially in children. Part 2 is a trial with gliclazide MR $60 \mathrm{mg}$ in patients with MODY1, MODY3 or MODY12 to investigate the efficacy (primary objective) and safety (secondary objective) of this treatment. Results of this Pan-India MODY study will provide important information about the prevalence of MODY and the effect of treatment with gliclazide MR $60 \mathrm{mg}$ in patients with MODY. 


\section{CONCLUSIONS}

Sulfonylureas are effective, well-tolerated and inexpensive treatments for $\mathrm{T} 2 \mathrm{DM}$, and are recommended as add-on therapy in evidencebased international consensus reports. These agents are also the first-line treatment of choice in the majority of patients with MODY. Among the available sulfonylureas, gliclazide is associated with the greatest beneficial impact on cardiovascular mortality, and the lowest incidence of severe hypoglycaemia. It is hoped that the results from the DIA-RAMADAN study and other analyses will provide new data on gliclazide MR and other second-line therapies.

\section{ACKNOWLEDGEMENTS}

Funding. The Rapid Service fee for publication of this article was funded by Servier Global Medical Affairs, France.

Medical Writing Assistance. The author would like to thank Catherine Rees of Springer Healthcare Communications, who provided medical writing assistance with the first draft of this manuscript. This medical writing assistance was funded by Servier, France.

Authorship. All named authors meet the International Committee of Medical Journal Editors (ICMJE) criteria for authorship for this article, take responsibility for the integrity of the work as a whole, and have given their approval for this version to be published.

Prior Presentation. This article was based on presentations given by the authors at the symposium "Real-world evidence and new perspectives with gliclazide MR" during the Annual Meeting of the International Diabetes Federation (IDF) in Busan, Korea, 4 December 2019.

Disclosures. Kamlesh Khunti has served as a consultant and participated in speaker bureaus for, or received research support from, Amgen, AstraZeneca, Berlin-Chemie AG/Menarini Group, BMS, Boehringer Ingelheim, Janssen,
Lilly, MSD, Napp, Novartis, Novo Nordisk, Roche, Sanofi and Servier. Mohamed Hassanein has attended advisory boards or received speaker honoraraia for Servier, MSD, Novartis, Novonordisk, Sanofi-Aventis, Astra Zeneca and Eli-Lily. Moon-Kyu Lee has received funding support and speaker honoraria from Merck, Novartis, Novo Nordisk, Astra Zeneca and Servier. Viswanathan Mohan has received funding support and speaker honoraria from Servier, Novo Nordisk, Sanofi, Merck, and other Indiabased pharmaceutical companies. Aslam Amod has served on advisory panels and participated in speaker bureaus and clinical trials for Aspen Pharmacare, AstraZeneca, Boehringer Ingelheim, Eli Lilly, MSD, Novartis, Novo Nordisk, Sanofi Aventis and Servier Laboratories.

Compliance with Ethics Guidelines. This article is based on previously conducted studies and does not contain any studies with human participants or animals performed by the authors.

Data Availability. Data sharing is not applicable to this article as no datasets were generated or analyzed during the current study.

Open Access. This article is licensed under a Creative Commons Attribution-NonCommercial 4.0 International License, which permits any non-commercial use, sharing, adaptation, distribution and reproduction in any medium or format, as long as you give appropriate credit to the original author(s) and the source, provide a link to the Creative Commons licence, and indicate if changes were made. The images or other third party material in this article are included in the article's Creative Commons licence, unless indicated otherwise in a credit line to the material. If material is not included in the article's Creative Commons licence and your intended use is not permitted by statutory regulation or exceeds the permitted use, you will need to obtain permission directly from the copyright holder. To view a copy of this licence, visit http:// creativecommons.org/licenses/by-nc/4.0/. 


\section{REFERENCES}

1. Sola D, Rossi L, Schianca GP, et al. Sulfonylureas and their use in clinical practice. Arch Med Sci. 2015;11(4):840-8.

2. Montvida O, Shaw J, Atherton JJ, Stringer F, Paul SK. Long-term trends in antidiabetes drug usage in the US: real-world evidence in patients newly diagnosed with type 2 diabetes. Diabetes Care. 2018;41(1):69-78.

3. Khunti K, Godec TR, Medina J, et al. Patterns of glycaemic control in patients with type 2 diabetes mellitus initiating second-line therapy after metformin monotherapy: retrospective data for 10256 individuals from the United Kingdom and Germany. Diabetes Obes Metab. 2018;20(2):389-99.

4. International Diabetes Federation (IDF) (2020) IDF Clinical practice recommendations for managing type 2 diabetes in primary care. 2017. https://www. idf.org/our-activities/care-prevention/type-2-diabetes. html. Accessed 21 Jan 2020.

5. Royal Australian College of General Practitioners (2020) General practice management of type 2 diabetes. 2016. https://www.racgp.org.au/FSDEDEV/ media/documents/Clinical\%20Resources/Guidelin es/Diabetes/General-practice-management-of-type2-diabetes_1.pdf. Accessed 21 Jan 2020.

6. Diabetes Canada Clinical Practice Guidelines Expert Committee, Houlden RL. Clinical practice guidelines. Can J Diabetes. 2018;42(1):S1-S325.

7. American Diabetes Association. Pharmacologic approaches to glycemic treatment: standards of medical care in diabetes-2019. Diabetes Care. 2019;42(1):S90-S102.

8. Davies MJ, D'Alessio DA, Fradkin J, et al. Management of hyperglycaemia in type 2 diabetes, 2018. A consensus report by the American Diabetes Association (ADA) and the European Association for the Study of Diabetes (EASD). Diabetologia. 2018;61(12):2461-98.

9. Grant PJ, Cosentino F. The 2019 ESC Guidelines on diabetes, pre-diabetes, and cardiovascular diseases developed in collaboration with the EASD: new features and the 'Ten Commandments' of the 2019 Guidelines are discussed by Professor Peter J. Grant and Professor Francesco Cosentino, the Task Force chairmen. Eur Heart J. 2019;40(39):3215-7.

10. Kalra S, Aamir AH, Raza A, et al. Place of sulfonylureas in the management of type 2 diabetes mellitus in South Asia: a consensus statement. Indian J Endocrinol Metab. 2015;19(5):577-96.
11. National Institute for Health and Care Excellence. Type 2 diabetes in adults: management. 2015. https://www.nice.org.uk/guidance/ng28/resources/ type-2-diabetes-in-adults-management-pdf-183733 8615493. Accessed 21 Jan 2020.

12. Cosentino F, Grant PJ, Aboyans V, et al. 2019 ESC Guidelines on diabetes, pre-diabetes, and cardiovascular diseases developed in collaboration with the EASD. Eur Heart J. 2020;41(2):255-32323.

13. Gerstein HC, Colhoun HM, Dagenais GR, et al. Dulaglutide and cardiovascular outcomes in type 2 diabetes (REWIND): a double-blind, randomised placebo-controlled trial. Lancet. 2019;394(10193): 121-30.

14. Holman RR, Bethel MA, Mentz RJ, et al. Effects of once-weekly exenatide on cardiovascular outcomes in type 2 diabetes. N Engl J Med. 2017;377(13): 1228-399.

15. Husain M, Birkenfeld AL, Donsmark M, et al. Oral semaglutide and cardiovascular outcomes in patients with type 2 diabetes. $\mathrm{N}$ Engl J Med. 2019;381(9):841-51.

16. Marso SP, Bain SC, Consoli A, et al. Semaglutide and cardiovascular outcomes in patients with type 2 diabetes. N Engl J Med. 2016;375(19):1834-44.

17. Marso SP, Daniels GH, Brown-Frandsen K, et al. Liraglutide and cardiovascular outcomes in type 2 diabetes. N Engl J Med. 2016;375(4):311-22.

18. Neal B, Perkovic V, Mahaffey KW, et al. Canagliflozin and cardiovascular and renal events in type 2 diabetes. N Engl J Med. 2017;377(7):644-57.

19. Perkovic V, Jardine MJ, Neal B, et al. Canagliflozin and renal outcomes in type 2 diabetes and nephropathy. N Engl J Med. 2019;380(24): 2295-306.

20. Pfeffer MA, Claggett B, Diaz R, et al. Lixisenatide in patients with type 2 diabetes and acute coronary syndrome. N Engl J Med. 2015;373(23):2247-57.

21. Wiviott SD, Raz I, Bonaca MP, et al. Dapagliflozin and cardiovascular outcomes in type 2 diabetes. N Engl J Med. 2019;380(4):347-57.

22. Zinman B, Wanner C, Lachin JM, et al. Empagliflozin, cardiovascular outcomes, and mortality in type 2 diabetes. N Engl J Med. 2015;373(22): 2117-288.

23. World Health Organization. Guidelines on secondand third-line medicines and type of insulin for the control of blood glucose in non-pregnant adults with diabetes mellitus. Geneva: World Health Organization; 2018. 
24. Zhang Y, McCoy RG, Mason JE, Smith SA, Shah ND, Denton BT. Second-line agents for glycemic control for type 2 diabetes: are newer agents better? Diabetes Care. 2014;37(5):1338-455.

25. Colagiuri S, Matthews D, Leiter LA, Chan SP, Sesti $G$, Marre $M$. The place of gliclazide $M R$ in the evolving type 2 diabetes landscape: a comparison with other sulfonylureas and newer oral antihyperglycemic agents. Diabetes Res Clin Pract. 2018;2018:1431.

26. Canadian Agency for Drugs and Technologies in Health. How much do diabetes drugs cost? 2018. https://www.cadth.ca/sites/default/files/pdf/diabetes_ cost_comparison_infographic.pdf. Accessed 21 Jan 2020.

27. Institute of Medicine (2011) Clinical practice guidelines we can trust. 2011. https://www.nap. edu/resource/13058/Clinical-Practice-Guidelines2011-Report-Brief.pdf.

28. AGREE Next Steps Consortium. Appraisal of guidelines for research and evaluation II: AGREE II instrument. 2013. https://www.agreetrust.org/wpcontent/uploads/2013/10/AGREE-II-Users-Manualand-23-item-Instrument_2009_UPDATE_2013.pdf. Accessed 21 Jan 2020.

29. Ekstrom N, Svensson AM, Miftaraj M, et al. Cardiovascular safety of glucose-lowering agents as add-on medication to metformin treatment in type 2 diabetes: report from the Swedish National Diabetes Register. Diabetes Obes Metab. 2016;18(10): 990-8.

30. Mogensen UM, Andersson C, Fosbol EL, et al. Sulfonylurea in combination with insulin is associated with increased mortality compared with a combination of insulin and metformin in a retrospective Danish nationwide study. Diabetologia. 2015;58(1): 50-8.

31. Zelniker TA, Wiviott SD, Raz I, et al. Comparison of the effects of glucagon-like peptide receptor agonists and sodium-glucose cotransporter 2 inhibitors for prevention of major adverse cardiovascular and renal outcomes in type 2 diabetes mellitus. Circulation. 2019;139(17):2022-31.

32. Lage MJ. Comment on generalizability of GLP-1 RA CVOTs in US T2D population. Am J Manag Care. 2019;25(4):170-1.

33. Pintat S, Fenici P, Hammar N, et al. Eligibility of patients with type 2 diabetes for sodium-glucose cotransporter 2 inhibitor cardiovascular outcomes trials: a global perspective from the DISCOVER study. BMJ Open Diabetes Res Care. 2019;7(1): e000627.
34. Wittbrodt ET, Eudicone JM, Bell KF, Enhoffer DM, Latham K, Green JB. Generalizability of glucagonlike peptide- 1 receptor agonist cardiovascular outcome trials enrollment criteria to the US type 2 diabetes population. Am J Manag Care. 2018;24(8): S146-S155155.

35. Hinton W, Feher M, Munro N, Walker M, de Lusignan S. Real-world prevalence of the inclusion criteria for the LEADER trial: data from a national general practice network. Diabetes Obes Metab. 2019;21(7):1661-7.

36. McGovern A, Feher M, Munro N, de Lusignan S. Sodium-glucose co-transporter 2 (SGLT2) inhibitor: comparing trial data and real-world use. Diabetes Ther. 2017;8(2):365-76.

37. Saunders C, Byrne CD, Guthrie B, et al. External validity of randomized controlled trials of glycaemic control and vascular disease: how representative are participants? Diabetes Med. 2013;30(3):300-8.

38. Azoulay L, Suissa S. Sulfonylureas and the risks of cardiovascular events and death: a methodological meta-regression analysis of the observational studies. Diabetes Care. 2017;40(5):706-14.

39. Roumie CL, Hung AM, Greevy RA, et al. Comparative effectiveness of sulfonylurea and metformin monotherapy on cardiovascular events in type 2 diabetes mellitus: a cohort study. Ann Intern Med. 2012;157(9):601-10.

40. Kahn SE, Haffner SM, Heise MA, et al. Glycemic durability of rosiglitazone, metformin, or glyburide monotherapy. N Engl J Med. 2006;355(23): 2427-43.

41. Rosenstock J, Perkovic V, Johansen OE, et al. Effect of linagliptin vs placebo on major cardiovascular events in adults with type 2 diabetes and high cardiovascular and renal risk: the CARMELINA randomized clinical trial. JAMA. 2019;321(1):69-79.

42. Vaccaro O, Masulli M, Nicolucci A, et al. Effects on the incidence of cardiovascular events of the addition of pioglitazone versus sulfonylureas in patients with type 2 diabetes inadequately controlled with metformin (TOSCA.IT): a randomised, multicentre trial. Lancet Diabetes Endocrinol. 2017;5(11): 887-97.

43. Ohkuma T, Zoungas S, Jun M, et al (2019) Intensive glucose-lowering and the risk of vascular events and premature death in patients with decreased kidney function: The ADVANCE trial. Diabetes Obes Metab. 2020;22(3):452-57.

44. Patorno E, Schneeweiss S, Gopalakrishnan C, Martin D, Franklin JM. Using real-world data to predict 
findings of an ongoing phase IV cardiovascular outcome trial: cardiovascular safety of linagliptin versus glimepiride. Diabetes Care. 2019;42(12): 2204-10.

45. UK Prospective Diabetes Study Group. Intensive blood-glucose control with sulphonylureas or insulin compared with conventional treatment and risk of complications in patients with type 2 diabetes (UKPDS 33). Lancet. 1998;352(9131):837-53.

46. Zoungas S, Patel A, Chalmers J, et al. Severe hypoglycemia and risks of vascular events and death. N Engl J Med. 2010;363(15):1410-8.

47. Khunti K, Chatterjee S, Gerstein HC, Zoungas S, Davies MJ. Do sulphonylureas still have a place in clinical practice? Lancet Diabetes Endocrinol. 2018;6(10):821-32.

48. Simpson SH, Lee J, Choi S, Vandermeer B, Abdelmoneim AS, Featherstone TR. Mortality risk among sulfonylureas: a systematic review and network meta-analysis. Lancet Diabetes Endocrinol. 2015;3(1):43-51.

49. Saremi A, Bahn GD, Reaven PD. A link between hypoglycemia and progression of atherosclerosis in the veterans affairs diabetes trial (VADT). Diabetes Care. 2016;39(3):448-54.

50. International Hypoglycaemia Study Group. Hypoglycaemia, cardiovascular disease, and mortality in diabetes: epidemiology, pathogenesis, and management. Lancet Diabetes Endocrinol. 2019;7(5): 385-96.

51. Marso SP, McGuire DK, Zinman B, et al. Efficacy and safety of Degludec versus Glargine in type 2 diabetes. N Engl J Med. 2017;377(8):723-32.

52. Mellbin LG, Ryden L, Riddle MC, et al. Does hypoglycaemia increase the risk of cardiovascular events? A report from the ORIGIN trial. Eur Heart J. 2013;34(40):3137-44.

53. Marx N, Rosenstock J, Kahn SE, et al. Design and baseline characteristics of the CARdiovascular outcome trial of LINAgliptin versus glimepiride in type 2 diabetes (CAROLINA(R)). Diab Vasc Dis Res. 2015;12(3):164-74.

54. Foley JE, Sreenan S. Efficacy and safety comparison between the DPP-4 inhibitor vildagliptin and the sulfonylurea gliclazide after two years of monotherapy in drug-naive patients with type 2 diabetes. Horm Metab Res. 2009;41(12):905-9.

55. Group AC, Patel A, MacMahon S, et al. Intensive blood glucose control and vascular outcomes in patients with type 2 diabetes. $\mathrm{N}$ Engl J Med. $2008 ; 358(24): 2560-72$.
56. Schernthaner G, Grimaldi A, Di Mario U, et al. GUIDE study: double-blind comparison of oncedaily gliclazide MR and glimepiride in type 2 diabetic patients. Eur J Clin Invest. 2004;34(8):535-42.

57. McGavin JK, Perry CM, Goa KL. Gliclazide modified release. Drugs. 2002;62(9):1357-64 (Discussion 65-66).

58. Dunkley AJ, Fitzpatrick C, Gray LJ, et al. Incidence and severity of hypoglycaemia in type 2 diabetes by treatment regimen: A UK multisite 12-month prospective observational study. Diabetes Obes Metab. 2019;21(7):1585-95.

59. Maloney A, Rosenstock J, Fonseca V. A model-based meta-analysis of 24 antihyperglycemic drugs for type 2 diabetes: comparison of treatment effects at therapeutic doses. Clin Pharmacol Ther. 2019;105(5):1213-23.

60. Maruthur NM, Tseng E, Hutfless S, et al. Diabetes medications as monotherapy or metformin-based combination therapy for type 2 diabetes: a systematic review and meta-analysis. Ann Intern Med. 2016;164(11):740-51.

61. Zaccardi F, Webb DR, Htike ZZ, Youssef D, Khunti $\mathrm{K}$, Davies MJ. Efficacy and safety of sodium-glucose co-transporter- 2 inhibitors in type 2 diabetes mellitus: systematic review and network meta-analysis. Diabetes Obes Metab. 2016;18(8):783-94.

62. Liu XY, Zhang N, Chen R, Zhao JG, Yu P. Efficacy and safety of sodium-glucose cotransporter 2 inhibitors in type 2 diabetes: a meta-analysis of randomized controlled trials for 1 to 2 years. J Diabetes Complicat. 2015;29(8):1295-303.

63. Mearns ES, Sobieraj DM, White CM, et al. Comparative efficacy and safety of antidiabetic drug regimens added to metformin monotherapy in patients with type 2 diabetes: a network metaanalysis. PLoS ONE. 2015;10(4):e0125879.

64. Hassanein M, Abdelgadir E, Bashier A, et al. The role of optimum diabetes care in form of Ramadan focused diabetes education, flash glucose monitoring system and pre-Ramadan dose adjustments in the safety of Ramadan fasting in high risk patients with diabetes. Diabetes Res Clin Pract. 2019;2019: 150288-95.

65. Hassanein M, Al Awadi FF, El Hadidy KES, et al. The characteristics and pattern of care for the type 2 diabetes mellitus population in the MENA region during Ramadan: an international prospective study (DAR-MENA T2DM). Diabetes Res Clin Pract. 2019;2019:151275-84.

66. Al Sifri S, Basiounny A, Echtay A, et al. The incidence of hypoglycaemia in Muslim patients with 
type 2 diabetes treated with sitagliptin or a sulphonylurea during Ramadan: a randomised trial. Int J Clin Pract. 2011;65(11):1132-40.

67. Aravind SR, Ismail SB, Balamurugan $\mathrm{R}$, et al. Hypoglycemia in patients with type 2 diabetes from India and Malaysia treated with sitagliptin or a sulfonylurea during Ramadan: a randomized, pragmatic study. Curr Med Res Opin. 2012;28(8): 1289-96.

68. Hassanein M, Abdallah K, Schweizer A. A doubleblind, randomized trial, including frequent patientphysician contacts and Ramadan-focused advice, assessing vildagliptin and gliclazide in patients with type 2 diabetes fasting during Ramadan: the STEADFAST study. Vasc Health Risk Manag. 2014;2014:10319-26.

69. Hassanein M, Al-Sifri S, Shaikh S, et al (2020) A realworld study in patients with type 2 diabetes treated with gliclazide modified release during fasting: DIARAMADAN. Diabetes Res Clin Pract.https://doi.org/ 10.1016/j.diabres.2020.108154.

70. Fajans SS, Bell GI. MODY: history, genetics, pathophysiology, and clinical decision making. Diabetes Care. 2011;34(8):1878-84.

71. Tattersall RB, Fajans SS. A difference between the inheritance of classical juvenile-onset and maturity-onset type diabetes of young people. Diabetes. 1975;24(1):44-53.

72. Ellard S, Bellanne-Chantelot C, Hattersley AT; European Molecular Genetics Quality Network (EMQN) MODY group. Best practice guidelines for the molecular genetic diagnosis of maturity-onset diabetes of the young. Diabetologia. 2008;51(4): 546-53.

73. Lachance $\mathrm{CH}$. Practical aspects of monogenic diabetes: a clinical point of view. Can J Diabetes. 2016;40(5):368-75.

74. Hattersley AT. Molecular genetics goes to the diabetes clinic. Clin Med (Lond). 2005;5(5):476-81.

75. Pearson ER, Starkey BJ, Powell RJ, Gribble FM, Clark PM, Hattersley AT. Genetic cause of hyperglycaemia and response to treatment in diabetes. Lancet. 2003;362(9392):1275-81.

76. Gujral UP, Pradeepa R, Weber MB, Narayan KM, Mohan V. Type 2 diabetes in South Asians: similarities and differences with white Caucasian and other populations. Ann NY Acad Sci. 2013;1281: 51-63.

77. Shah A, Kanaya AM. Diabetes and associated complications in the South Asian population. Curr Cardiol Rep. 2014;16(5):476.

78. Mohan V, Radha V, Nguyen TT, et al. Comprehensive genomic analysis identifies pathogenic variants in maturity-onset diabetes of the young (MODY) patients in South India. BMC Med Genet. 2018;19(1):22.

79. Unnikrishnan R, Shah VN, Mohan V. Challenges in diagnosis and management of diabetes in the young. Clin Diabetes Endocrinol. 2016;2:18. https://doi.org/10.1186/s40842-016-0036-6. 